\title{
O constitucionalismo pluralista e o desenvolvimento humano: estudo comparado das experiências do Peru e da Bolívia
}

\author{
Pluralist constitutionalism and human development: a comparative study of the \\ experiences of Peru and Bolivia
}

\author{
Gina Vidal Marcílio Pompeu* \\ Jessica Ramos Sabóia**
}

\section{Resumo}

\begin{abstract}
Por meio do presente estudo tem-se como propósito analisar a necessidade de reconhecimento das diversidades dos direitos coletivos e a influência do constitucionalismo pluralista no desenvolvimento humano por meio de estudo comparado do Peru e da Bolívia. Incluir o direito dos povos indígenas entre as prioridades políticas constitui desafio jurídico e econômico na América Latina. A metodologia utilizada foi analítica, empírica e crítica, com a investigação do tipo documental-bibliográfica, pesquisa pura de abordagem qualitativa, descritiva e exploratória quanto aos objetivos. Objetiva-se discutir o constitucionalismo latino-americano e a tendência plurinacional, e demonstrar a efetividade constitucional e a necessidade de cooperação entre o público e o privado no reconhecimento dos povos indígenas para a conciliação do desenvolvimento humano com o crescimento econômico. Entende-se que a Constituição da Bolívia é plurinacional, assim mais avançada no ciclo progressivo do que a do Peru, que é pluricultural. Pondera-se, contudo, que apenas reconhecimentos formais de direitos e garantias dos povos indígenas, com constituições plurinacionais, não garantem desenvolvimento humano, principalmente se não se fizerem acompanhadas pela democratização econômica.
\end{abstract}

Palavras-chave: Constitucionalismo. Plurinacional. Povos indígenas. América Latina. Desenvolvimento Humano.

\section{Abstract}

The purpose of this study is to analyze the need to recognize the diversity of collective rights and the influence of pluralistic constitutionalism on human development through a comparative study of Peru and Bolivia. Including the right of indigenous peoples to political priorities is a legal and economic challenge in Latin America. The methodology used was analytical, empirical and critical, with research of the documentary-bibliographic type, pure research with a qualitative, descriptive and exploratory approach to the objectives. The objective is to discuss Latin American constitutionalism and the plurinational trend, and to demonstrate constitutional effectiveness and the need for cooperation between the public and the private sector in the recognition of indigenous peoples for the reconciliation of human development with economic growth. It is understood that the Constitution of Bolivia is plurinational, so more advanced in the progressive cycle than that of Peru, which is pluricultural. However, it is considered that only formal recognition of the law and guarantees of indigenous peoples, with plurinational constitutions, do not guarantee human development, especially if they are not accompanied by economic democratization.

Keywords: Constitutionalism. Plurinational. Indian people. Latin America. Human development.

\footnotetext{
Doutorado em Direito pela Universidade Federal de Pernambuco (2004). Mestrado em Direito (Direito e Desenvolvimento) pela Universidade Federal do Ceará (1994). Advogada. Coordenadora e Professora do Programa de Pós-Graduação em Direito Constitucional da Universidade de Fortaleza - Mestrado e Doutorado. Professora convidada da Faculdade de Direito da Universidade do Havre. Professora Convidada da Faculdade de Jurisprudência da Universidade de Palermo. Pesquisadora de Pós-Doutorado das Faculdades de Direito da Universidade de Lisboa e do Havre. Consultora Jurídica da Assembleia Legislativa do Estado do Ceará. Membro associado do Conselho de Pesquisa e Pós Graduação em Direito - CONPEDI e da Associação Brasileira de Ensino do Direito ABEDi. Fortaleza-CE-Brasil. E-mail: ginapompeu@unifor.br.

** Mestranda em Direito Constitucional no Programa de Pós-Graduação em Direito Constitucional da Universidade de Fortaleza (PPGD Unifor). Membro do Laboratório de Ciências Criminais (LACRIM) da Unifor. Advogada. Fortaleza-CE-Brasil. E-mail: jessicarsaboia@gmail.com.
} 


\section{Introdução}

Apesar da globalização se construir em torno de uma ordem mundial hierárquica e desregulada de alta competição que, em geral, dita as próprias regras, a reflexão acerca dos direitos humanos tem se fortalecido na contemporaneidade. A construção histórica dos direitos humanos obedeceu à ordem lógica, ética, filosófica, histórica e, sobretudo, econômica. Nota-se que os direitos humanos são frutos de processo de construção e afirmação inerente a cada contexto. Verifica-se, no século XXI, um movimento jurídico e político que redefine e reinterpreta os direitos humanos, denominado constitucionalismo pluralista latinoamericano.

A América Latina experimentou, em diferentes velocidades e com traços heterogêneos, segundo os países, significativos progressos em seu desenvolvimento econômico e social, contudo esses avanços encontram limites em relação à heterogeneidade estrutural, à vulnerabilidade externa e à persistência de altos níveis de desigualdade. Um dos maiores desafios enfrentados é reconhecer os direitos coletivos e incluir os direitos dos povos indígenas entre as prioridades políticas. O aparato legal garantista, emancipador e pluralista muitas vezes, nesse contexto, não se realiza de forma efetiva.

Dessa forma, a pesquisa busca verificar a influência do constitucionalismo pluralista, que é uma tendência contemporânea, no desenvolvimento humano por meio de estudo comparado do Peru e da Bolívia. Inicialmente, analisa-se o constitucionalismo latino-americano e demonstra-se a importância dos movimentos sociais para esta nova tendência. Em seguida, trata-se acerca dos aspectos constitucionais do Peru e da Bolívia para verificar a complexidade e detalhamento dos respectivos textos. Ao final, por meio da comparação de dados entre os dois países, apresenta-se a relevância do reconhecimento normativo e social dos povos indígenas para o desenvolvimento humano.

A investigação utilizada é do tipo documental-bibliográfica, realizada em livros, artigos de periódicos e trabalhos monográficos que abordam direta ou indiretamente o tema, além da análise de dados estatísticos oriundos de organismos internacionais. A pesquisa é pura, pois tem como objetivo a ampliação dos conhecimentos. É qualitativa, uma vez que busca apreciar a abordagem atual sobre o tema no ordenamento jurídico latino-americano; descritiva, pois descreve, explica o problema apresentado; e exploratória, pois busca aprimorar as ideias sobre o tema. Em outras palavras, a metodologia utilizada é analítica, empírica e crítica.

O pluralismo é uma das tendências e inovações mais significativas introduzidas pelas recentes constituições latino-americanas, pois aponta para uma reapropriação dos elementos do Estado Constitucional e revisita de forma crítica e criativa suas promessas não cumpridas e premissas não consideradas. Portanto, a presente pesquisa tem como escopo o estudo do constitucionalismo latinoamericano e sua influência no desenvolvimento humano, bem como a importância da cooperação entre os setores público e privado na efetivação do Estado plurinacional e do pluralismo jurídico.

\section{Constitucionalismo latino-americano e a tendência plurinacional}

Na América Latina, tanto a cultura jurídica imposta pelas metrópoles ao longo do período colonial quanto as instituições jurídicas formadas após o processo de independência derivam da tradição legal europeia, representada pelas fontes clássicas dos Direitos romano, germânico e canônico. Igualmente, na formação da cultura jurídica e do processo de constitucionalização latino-americano pós-independência, tem-se a herança das constituições políticas burguesas e dos princípios iluministas inerentes às declarações de direitos, bem como provenientes da nova modernidade capitalista, de livre mercado, pautada na tolerância e no perfil liberal-individualista (WOLKMER; FAGUNDES, 2011, p. 376).

Então, faz parte da tradição das constituições políticas latino-americanas a consagração, pelo menos abstratamente, de garantia liberal de direitos, independência de poderes, igualdade formal perante a lei, soberania popular, cidadania culturalmente homogênea e condição idealizada de um Estado de Direito universal. 
Contudo, na prática, as instituições jurídicas são marcadas por formas de democracia excludente; sistema representativo clientelista; experiências de participação elitista; controle centralizado e burocrático do poder oficial; e por ausências históricas das grandes massas campesinas e populares (WOLKMER; FAGUNDES, 2011, p. 377).

Entende-se, assim, que os documentos legais e os textos constitucionais elaborados na América Latina, em grande parte, têm sido a expressão da vontade e do interesse de setores das elites hegemônicas formadas e influenciadas principalmente pela cultura europeia. Para Guillermo O'Donnell (2007, p. 162), a "América Latina tiene una extensa tradicion de ignorar la ley o, cuando se la reconoce, de manipularla em favor de los poderosos y para la represión o contención de vulnerables y adversários."

Nesse contexto, não há contribuição para o desenvolvimento humano quando se manipula a lei para beneficiar uma parte da população, que normalmente é a minoria numérica, principalmente quando o discurso é a proteção do bem comum, pois tais textos normativos desconsideram a diversidade existente nos países, então o bem comum pode prejudicar grande parte da população. "Assim, o benefício geral não pode ser uma boa razão para a restrição dos direitos, mesmo quando o benefício em questão for um elevado respeito pela lei" (DWORKIN, 2002, p. 296).

Na história da região, raras vezes as constituições liberais e a doutrina clássica do constitucionalismo político reproduziram materialmente as necessidades de seus segmentos sociais majoritários, como as nações indígenas, as populações afro-americanas, as massas de campesinos agrários e os múltiplos movimentos urbanos. Isto demonstra a presença de uma Constituição simbólica que prevê direitos e garantias para todos, mas desvaloriza grande parte da população como sujeito de direitos.

Para cumprir as promessas democráticas e o projeto descolonizador, surgiram, recentemente, novos movimentos do constitucionalismo em países sul-americanos, a exemplo da Bolívia, que tentam romper com a lógica liberal-individualista das constituições políticas tradicionalmente operadas e reinventam o espaço público a partir dos interesses e necessidades das maiorias alijadas historicamente dos processos decisórios. Aduz, no mesmo sentido, que:

Nos anos 2000, a América Latina surpreendeu o mundo com seus movimentos sociais populares radicais do Equador, na Bolívia, na Argentina, na Venezuela, no México, no Brasil, ao contestar o modelo de ajuste neoliberal que reinou de forma absoluta, por mais de uma década e que, então, revelava sinais de esgotamento. (CARVALHO, 2010, p. 184).

As novas constituições surgidas são uma quebra ou ruptura com a antiga matriz eurocêntrica de pensar o Direito e o Estado para o continente, voltando-se, atualmente, para a refundação das instituições, a transformação das ideias e dos instrumentos jurídicos em favor dos interesses e das culturas encobertas e violentamente apagadas da sua própria história (WOLKMER, 2011, p. 377-378).

O constitucionalismo latino-americano está relacionado com a exigência popular por melhores condições de vida e busca refundar as instituições políticas e jurídicas, com prioridade a riqueza cultural diversificada, respeitadas as tradições comunitárias históricas e superado o modelo de política exclusivista, comprometida com as elites dominantes e a serviço do capital externo.

Esse movimento é bastante importante, pois a Constituição não deve ser apenas simbólica e reconhecer formalmente direitos, deve ser efetivada na prática, garantindo um bem-estar para todos aqueles que fazem parte daquela sociedade, sejam minoria ou maioria numéricas, além de reconhecer os direitos coletivos de uma comunidade específica. Nesse contexto, percebe-se que:

A constituição em si não só disciplina e limita o exercício do poder institucional, como também busca compor as bases de uma dada organização social e cultural, reconhecendo e garantindo os direitos conquistados de seus cidadãos, materializando o quadro real das forças sociais hegemônicas e das forças não dominantes (WOLKMER; FAGUNDES, 2011, p. 373).

A constituição abandona o âmbito exclusivista das minorias hegemônicas para atender ao chamado de outra forma de poder diversificado, multifacetado e plural. O constitucionalismo latino-americano 
tem como tendência contemporânea a plurinacionalidade, que proporciona uma reinvenção do Estado, reinterpretação da concepção do direito e da justiça no processo de inovação jurídica e política das instituições reconstituídas desde a realidade colonial.

Em outras palavras, "há uma proposta de nova institucionalização do Estado, o chamado Estado plurinacional, baseado em novas autonomias, no pluralismo jurídico, em um novo regime político calcado na democracia intercultural e em novas individualidades particulares e coletivas." (LOUREIRO; MARTINS; SILVA, 2016, p. 370-371).

A interculturalidade, crítica à cultura hegemônica excludente, indica um caminho de inclusão, de encontro qualitativo e solidário com o outro, que possibilita a aceitação do diferente como uma oportunidade de enriquecimento e transformação de todos (BRAGATO; BARRETTO; SILVEIRA FILHO, 2017, p. 54).

Como afirma Alba de Carvalho (2010, p. 175), "vivemos, hoje, um momento de expansão do capital que parece não ter limites e controles, a acirrar contradições, antagonismos e desigualdades". Dessa forma, em resposta a este momento atual, as tendências constitucionais contemporâneas rompem com as doutrinas tradicionais e as práticas excludentes das sociedades marcadas pela violência, dominação e opulência das minorias detentoras do poder sobre maiorias desagregadas como força política.

Para Antonio Carlos Wolkmer (2001, p. 172), o pluralismo é "a existência de mais de uma realidade, de múltiplas formas de ação prática e da diversidade de campos sociais ou culturais com particularidade própria, ou seja, envolver o conjunto de fenômenos autônomos e elementos heterogêneos que não se reduzem entre si.". Na composição e dinâmica do pluralismo, compreende-se a interdependência na diversidade de instituições sociais como igrejas, sindicatos, associações civis e empresas (WOLKMER; FAGUNDES, 2011, p. 374).

O constitucionalismo plurinacional é um tipo de constitucionalismo novo, baseado em trocas interculturais igualitárias que redefinem e reinterpretam os direitos humanos constitucionais. O Estado plurinacional e intercultural deve ser dialógico, concretizante e garantista. Portanto, entende-se que:

En el lenguaje de los derechos humanos, la plurinacionalidad implica el reconocimiento de derechos colectivos de los grupos sociales en situaciones en que los derechos individuales de las personas que los integran resultan ineficaces para garantizar el reconocimiento y la persistencia de su identidad cultural o el fin de la discriminación social de que son víctimas (SANTOS, 2010, p. 81).

A plurinacionalidade é uma maneira profunda de reconhecimento da diversidade, com ênfase na solidariedade. É uma tendência emancipadora em que há uma articulação de múltiplas culturas e o respeito às diferenças e aos direitos coletivos em vez de igualdade em homogeneidades abstratas e redução de complexidades.

Além disso, para fazer cumprir os princípios do constitucionalismo plural, deve-se superar a visão do Estado enquanto fonte única do direito por ele assinado e vigente, pois o pluralismo no Direito tende a demonstrar que este ente deixa de ser fonte exclusiva de todo o Direito quando há o reconhecimento de outros direitos e outras culturas, haja vista que há a necessidade de buscar mecanismos de coordenação e cooperação para o desenvolvimento humano e econômico nesse novo contexto.

Segundo Lucas Pizzolatto Konzen (2010, p. 248), o pluralismo jurídico se revela na percepção da prática espacial conflituosa da luta social entre a hegemonia das representações do espaço concebidas pelo capital e na resistência dos espaços de representação vivenciados pelos movimentos sociais urbanos. As experiências latino-americanas demarcam uma tendência emergente no contexto de uma contrahegemonia, sobretudo no âmbito de governos que são identificados como "de esquerda", o que impõe uma reflexão acerca do padrão de políticas públicas (CARVALHO, 2010, p. 195).

Vale comentar que o constitucionalismo latino-americano prevê ciclos progressivos, quais sejam: o multicultural, ciclo social e descentralizador que reconhece a diversidade cultural como fator constitutivo da sociedade; o pluricultural, ciclo participativo popular e pluralista, que reconhece os direitos à identidade 
étnica e à diversidade cultural, além da qualificação do próprio Estado como pluricultural, o que significa a inclusão das fontes do direito consuetudinário indígena nos textos constitucionais; e o plurinacional, que radicaliza o projeto constitucional descolonizador, propondo o desafio de refundar o Estado a partir do reconhecimento dos povos indígenas não apenas como culturas diversas, mas, sobretudo, como nações originárias ou nacionalidades com autodeterminação (LOUREIRO; MARTINS; SILVA, 2016, p. 372-379).

Um exemplo do primeiro ciclo, denominado de multicultural, é a Constituição Brasileira de 1988, principalmente os artigos 231 e $232 .{ }^{1}$ Nota-se que, apesar das ideias de multiculturalismo e do reconhecimento de direitos indígenas, não há recepção explícita nos textos constitucionais do direito consuetudinário ou da jurisdição indígena como formas de manifestação de um verdadeiro pluralismo jurídico.

No segundo ciclo, pluricultural, tem-se a constituição da Venezuela de 1999 e a do Peru de 1993, que introduzem fórmulas de pluralismo jurídico. Além disso, a Constituição peruana, objeto do próximo tópico, prevê idiomas indígenas como oficiais. ${ }^{2} \mathrm{E}$, no terceiro ciclo, tem-se a Constituição da Bolívia, que é mais ampla, complexa e detalhada, radicada na realidade histórico-cultural do país, que será analisada a seguir.

\section{Perspectivas gerais e constitucionais do Peru e da Bolívia}

Os povos pré-colombianos da América Latina, conforme abordado anteriormente, foram chamados a contribuir com a integralidade de sua cultura e convocados a renunciar a sua dignidade por meio da escravização forçada ou do genocídio. Então, tradicionalmente excluídos do processo econômico e decisório, os integrantes dessas nações foram sistematicamente expropriados dos seus conhecimentos e se viram subordinados à ordem jurídica imposta, que lhes negava a condição de sujeito de direitos.

Importante ressaltar que se deve a Simon Bolívar os créditos pela libertação de grande parte da América do Sul. Ele queria formar uma nação com os países conquistados por ele: Equador, Venezuela, Peru e Bolívia. Contudo, não conseguiu manter a Confederação dos Países da América do Sul, pois havia uma instabilidade política e diversas manifestações de nacionalismo (CARVALHO; POMPEU, 2010, p. 160-161).

A independência das colônias na América Latina não representou uma mudança total e definitiva com relação à Espanha e Portugal, mas tão somente uma reestruturação, sem uma ruptura significativa na ordem social, econômica e político-constitucional. Aos poucos, incorporaram-se e adaptaram-se princípios do ideário econômico capitalista, da doutrina do liberalismo individualista e da filosofia positivista. Todavia, apenas na contemporaneidade é que foram reconhecidas as heterogeneidades, as diversidades culturais e as diferenças a fim de efetivar o princípio da igualdade.

\footnotetext{
“Art. 231. São reconhecidos aos índios sua organização social, costumes, línguas, crenças e tradições, e os direitos originários sobre as terras que tradicionalmente ocupam, competindo à União demarcá-las, proteger e fazer respeitar todos os seus bens. $\S 1^{\circ}$ São terras tradicionalmente ocupadas pelos índios as por eles habitadas em caráter permanente, as utilizadas para suas atividades produtivas, as imprescindíveis à preservação dos recursos ambientais necessários a seu bem-estar e as necessárias a sua reprodução física e cultural, segundo seus usos, costumes e tradições. $\S 2^{\circ}$ As terras tradicionalmente ocupadas pelos índios destinam-se a sua posse permanente, cabendo-lhes o usufruto exclusivo das riquezas do solo, dos rios e dos lagos nelas existentes. $\S 3^{\circ} \mathrm{O}$ aproveitamento dos recursos hídricos, incluídos os potenciais energéticos, a pesquisa e a lavra das riquezas minerais em terras indígenas só podem ser efetivados com autorização do Congresso Nacional, ouvidas as comunidades afetadas, ficando-lhes assegurada participação nos resultados da lavra, na forma da lei. $\S 4^{\circ}$ As terras de que trata este artigo são inalienáveis e indisponíveis, e os direitos sobre elas, imprescritíveis. $\S 5^{\circ}$ É vedada a remoção dos grupos indígenas de suas terras, salvo, "ad referendum" do Congresso Nacional, em caso de catástrofe ou epidemia que ponha em risco sua população, ou no interesse da soberania do País, após deliberação do Congresso Nacional, garantido, em qualquer hipótese, o retorno imediato logo que cesse o risco. $§ 6^{\circ}$ São nulos e extintos, não produzindo efeitos jurídicos, os atos que tenham por objeto a ocupação, o domínio e a posse das terras a que se refere este artigo, ou a exploração das riquezas naturais do solo, dos rios e dos lagos nelas existentes, ressalvado relevante interesse público da União, segundo o que dispuser lei complementar, não gerando a nulidade e a extinção direito a indenização ou a ações contra a União, salvo, na forma da lei, quanto às benfeitorias derivadas da ocupação de boa fé. $\S 7^{\circ}$ Não se aplica às terras indígenas o disposto no art. $174, \S 3^{\circ}$ e $\S 4^{\circ}$. Art. 232 . Os índios, suas comunidades e organizações são partes legítimas para ingressar em juízo em defesa de seus direitos e interesses, intervindo o Ministério Público em todos os atos do processo." (BRASIL, 1988).

2 "Art. 48. Son idiomas oficiales el castellano y, en las zonas donde predominen, también lo son el quechua, el aimara y las demás lenguas
} aborígenes, según la ley. - PERU. República do. Constitucion política del Perú de 1993". 
A história do Peru e da Bolívia, focos do presente tópico, é marcada por guerrilhas, dependências políticas ditatoriais, desigualdades sociais e atraso econômico, porém a afirmação nacionalista e a busca por alcançar o desenvolvimento são atualmente motores do pensamento ideológico que está proporcionando a transformação dos países periféricos (FURTADO, 1968, p. 17).

O Peru, ou República do Peru, tem uma superfície de $1.285 .220 \mathrm{~km}^{2}$, faz fronteira com Brasil, Chile, Bolívia, Colômbia, Equador e Oceano Pacífico, e tem uma população total aproximada de 32.167 milhões de habitantes, com uma taxa de pobreza de $22,7 \%$, de acordo com o seu perfil nacional sócio-demográfico (CEPAL, 2017a, online).

Conforme a Constituição de 1993, o Peru é uma República presidencialista democrática, em que o presidente é o chefe de Estado e de Governo. Atualmente, é Pedro Pablo Kuczynski. A Constituição do Peru tem 206 artigos e já demonstra em seu preâmbulo um vínculo religioso. Segundo o artigo $3^{\circ}$ de sua Constituição, o Peru se considera um estado democrático de Direito com a forma republicana de governo. Após a sua independência, em 1821, passou por períodos de alternância entre turbulência política e crise fiscal e estabilidade e crescimento econômico.

O Estado tem como finalidade, de acordo com o artigo $1^{\circ}$ da Constituição, a defesa da pessoa humana e o respeito a sua dignidade. Além disso, a Constituição prevê que a identidade étnica e cultural são direitos fundamentais da pessoa, e deve o Estado reconhecer e proteger a pluralidade étnica e cultural da nação (artigos $2^{\circ}$ e 19 ).

A partir do artigo 43, entende-se que a República do Peru é democrática, social, independente e soberana. O Estado é uno e indivisível, com governo unitário, representativo e descentralizado, e organizase segundo o princípio da separação de poderes. Todo o poder emana do povo que é soberano (artigo 45) e a Constituição tem supremacia (artigo 51). O Estado respeita a identidade cultural e reconhece que as comunidades nativas têm existência legal e são pessoas de direito ou jurídicas.

$\mathrm{O}$ acesso à justiça é previsto no artigo $2^{\circ}$, este aduz que existe um direito fundamental a peticionar de forma individual ou coletiva e receber uma resposta dentro do prazo legal. De forma complementar, o artigo 115 aduz a garantia do devido processo legal e defesa de uma justiça plural, pronta, oportuna, gratuita, transparente e sem dilações.

Ainda há previsão constitucional sobre a defensoria pública nos artigos 161 e 162, e de formas de pluralismo jurídico (artigo 149), em que se põe em questão a ideia clássica de soberania e monopólio que as Constituições assinalavam aos poderes ou órgãos soberanos. Então, deduz-se que não só somente são direito as normas produzidas pelos órgãos soberanos do Estado (poderes legislativo, executivo e judiciário), mas são reconhecidas as autoridades indígenas, com suas normas e procedimentos, ou seu direito consuetudinário, e funções jurisdicionais, ou de justiça (LOUREIRO; MARTINS; SILVA, 2016, p. 376).

A Constituição do Peru pode ser considerada pluricultural, pois garante os direitos à identidade étnica e à diversidade cultural e tem o Estado qualificado como pluricultural, haja vista a existência dos idiomas indígenas como oficiais, segundo o artigo 48, conforme exposto no tópico anterior, e a consideração do direito consuetudinário indígena como fonte de produção do direito com o pluralismo jurídico.

Assim como o Peru, quando os espanhóis chegaram ao continente latino-americano, o território que hoje é parte da Bolívia formava parte do Império Inca. A formação do Estado bolivariano ocorreu com o reconhecimento jurídico e político da pluralidade de culturas e povos que habitam o território nacional. Atualmente, seu constitucionalismo é considerado plurinacional (LOUREIRO; MARTINS; SILVA, 2016, p. 378-379).

Contudo, nem mesmo na época pré-hispânica, e muito menos na Colônia ou na República, a diversidade de povos foi assumida em um plano de igualdade. Vale ressaltar que desde a época colonial a diversidade foi motivo de discriminação, domínio e exclusão. Segundo Raúl Llasag Fernández (2014, p. 289), não é suficiente apenas previsão constitucional ou legislativa sobre o respeito à diversidade, pois 
"os processos descolonizadores na prática requerem transformações em diferentes níveis ou espaços: individual, familiar, comunitário, local, nacional e até mesmo internacional."

No início do século XXI, o movimento indígena viveu um processo de fortalecimento e de construção de laços muito fortes com outros setores sociais, o que ocasionou, nas eleições gerais de dezembro de 2005, na Bolívia, a vitória do líder Evo Morales e do Movimento ao Socialismo (MAS) nas eleições com $54 \%$ dos votos. Uma vez no poder, por mandato dos movimentos indígenas, Evo Morales apresentou o projeto de convocação da Assembleia Constituinte (FERNÁNDEZ, 2014, p. 280-281).

A eleição de Evo Morales pode ser atribuída a importantes fatores estruturais, como a persistente pobreza entre a população indígena, e a diversos fatores de conjuntura, como o seu carisma e perspicácia política, o momento da eleição ter coincidido com a "Revolução Bolivariana" contra o "neoliberalismo", liderada por Hugo Chávez, e a política externa norte-americana ter se concentrado de maneira excessiva no combate às drogas e ao terrorismo.

A Assembleia Constituinte teve várias dificuldades desde sua Lei de Convocação. Depois de uma complexa disputa com a oposição regional e de um difícil processo de elaboração, negociação política e modificação, no dia 9 de dezembro de 2007, a Assembleia aprovou o projeto de Constituição e, no dia 14 de dezembro de 2007, encaminhou-o ao Congresso Nacional, que realizou algumas modificações e aprovou o texto constitucional em outubro de 2008. Em 25 de janeiro de 2009, o texto foi submetido ao referendo popular e aprovado pelo povo bolivariano com $61,43 \%$ dos votos. A Constituição plurinacional foi promulgada e publicada no Diário Oficial no dia 7 de fevereiro de 2009 (FERNÁNDEZ, 2014, p. 281-282).

A Bolívia, ou Estado Plurinacional da Bolívia, tem uma superfície de $1.098 .580 \mathrm{~km}^{2}$, faz fronteira com Argentina, Chile, Paraguai, Brasil e Peru, e tem uma população total aproximada de 11.071 milhões de habitantes, com uma taxa de pobreza de $32,7 \%$, de acordo com o seu perfil nacional sócio-demográfico (CEPAL, 2017b, online).

AConstituição tem 411 artigos, com o cidadão como quinto poder presente no controle social. Segundo o artigo 7, o povo é soberano e exerce a soberania de forma direta e delegada Há uma proeminência do Poder Executivo e uma grande intervenção pública na economia. De acordo com o artigo 12, existem os poderes Legislativo, Executivo, Judiciário e Eleitoral, e a organização do estado se dá pela independência, separação, coordenação e cooperação entre esses poderes.

O preâmbulo da Constituição já traz que o Estado bolivariano é baseado no respeito e na dignidade entre todos, com princípios de soberania, dignidade, complementariedade, solidariedade, harmonia e equidade na distribuição e redistribuição do produto social. Além do respeito à pluralidade econômica, social, jurídica, política e cultural.

A Constituição bolivariana, ao se preocupar em redescobrir seus valores, tradições e movimentos locais, não cuidou com o mesmo zelo da integração global. Portanto, há certa exclusão da Bolívia de parte do processo de integração internacional. Apesar disso, vale ressaltar que a norma constitucional, a exemplo da bolivariana no artigo 13, incorpora normas internacionais de proteção dos direitos humanos com status de normas constitucionais. Há dois instrumentos internacionais importantes sobre a temática indígena: a Convenção 169 da Organização Internacional do Trabalho (OIT-1989) e a Declaração das Nações Unidas sobre os Direitos dos Povos Indígenas (2007).

A Bolívia é uma República democrática. A Constituição Bolivariana declara como plurinacionais algumas instituições do Estado. Dessa forma, a Bolívia é um Estado plurinacional e intercultural de transição. A partir dessa tendência contemporânea, deve-se rever o Estado moderno dentro dos anseios populares e comunitários:

Entonces está aquí la idea de que la plurinacionalidad obliga, mas obviamente, a refundar el Estado moderno, porque el Estado moderno, como vamos a ver, es un Estado que tiene una sola nación, $y$ en este momento hay que combinar diferente conceptos de nación dentro de un mismo Estado. La interculturalidad tiene esta característica que no es simplemente cultural, sino también política y, 
además, presupone una cultura común. No hay interculturalidad si no hay una cultura común, una cultura compartida (SANTOS, 2009, p. 202).

No artigo $1^{\circ}$, a Bolívia demonstra que se funda na pluralidade, com respeito à soberania dos estados, e considera-se um Estado unitário social de direito plurinacional; comunitário; livre e independente; soberano; democrático; intercultural; descentralizado e com autonomias. A constituição prevê ainda a livre determinação dos povos indígenas no território nacional, e traz como idiomas oficiais o castelhano e todos os idiomas nacionais dos povos indígenas originários.

A população indígena na Bolívia é a maior da América Latina em relação à população do país, como se verá no próximo tópico. $\mathrm{E}$ a Constituição garante um vasto conjunto de direitos aos povos indígenas (artigo 30). A visão do índio não busca a eliminação do outro, e sim a redefinição de um novo equilíbrio, voltado necessariamente a implicar a redistribuição de renda e a redução de privilégios e superlucros dos setores mais abastados. Por isso, entende-se que:

\begin{abstract}
Ao que parece, não há duvida de que a proposta de refundação dos Estados, ou seja, a transformação dos Estados coloniais, capitalistas, patriarcais ou monoculturais em Estados plurinacionais e interculturais como transição para uma nova forma de organização social, política e econômica nasce de setores tradicionalmente marginalizados, excluídos e invisibilizados e, em especial, dos movimentos indígenas; assim, essa proposta vai muito além de uma simples refundação do Estado (FERNÁNDEZ, 2014, p. 267).
\end{abstract}

O artigo 24 traz o acesso à justiça como uma espécie de direito civil, prevendo o direito de peticionar individualmente ou de forma coletiva e de receber uma resposta formal. Ainda há previsão constitucional sobre a defensoria pública, nos artigos 218 a 224. Além disso, nos artigos 190 a 192, há a incorporação do pluralismo jurídico e do direito de aplicação da justiça indígena paralela à juridicidade estatal, e reconhece a manifestação periférica de outro modelo de justiça e de legalidade.

Nesse sentido, depreende-se que a Constituição da Bolívia se encontra em um ciclo mais avançado do que a do Peru, haja vista que reconhece os povos indígenas como nações. Para a concretização dessa constituição plurinacional, deve-se incluir essas nações nas políticas públicas e nas atividades vindas dos interesses privados, além do reconhecimento dos direitos e garantias e da diversidade cultural.

\title{
4 Uma análise comparativa de dados do Peru e da Bolívia: a influência do pluralismo constitucional para o desenvolvimento humano
}

A América Latina é feita de tensões e contradições histórias entre os elementos de seu modo de desenvolvimento. Para Alain Touraine (1989, p. 32-33), "o crescimento econômico não acarreta nem a integração social nem a diminuição das desigualdades. Ao contrário, a América Latina é cada vez mais marcada pela desigualdade e a manutenção de vastas zonas de subdesenvolvimento ou de miséria".

O modo de desenvolvimento latino-americano combina elementos negativos, como os decorrentes dos limites a formação de uma sociedade industrial pelo capitalismo dependente e pela heterogeneidade estrutural, e os positivos, como os decorrentes da formação de uma sociedade industrial pela taxa elevada de investimentos e pela grande participação político-cultural urbana (TOURAINE, 1989, p. 43-44).

Depois do fim da guerra fria, num mundo globalizado e pluricultural, o destaque dado aos povos indígenas e sua agenda de direitos (em um fenômeno que não é exclusivo da região, mas um processo global) faz parte de uma diversidade de lutas pelo reconhecimento e dignidade humana. Além disso, "o século $\mathrm{XXI}$, em tempos de globalização econômica e do acesso à informação, trouxe ao ser humano a consciência coletiva do bem-estar e de suas liberdades." (POMPEU, 2008, p. 1332).

Dessa forma, para o aumento do desenvolvimento humano e o reconhecimento da dignidade humana de todos, deve-se incluir os direitos dos povos indígenas entre as prioridades políticas, principalmente em países que tem grande concentração desses povos, a exemplos dos países da América Latina. 
A luta dos povos indígenas pela defesa e reconhecimento de seus direitos foi persistente na história. Então, "as lutas pela ampliação a consolidação de direitos, hoje, colocam, na cena política, sujeitos que viviam nas sombras de processos de exclusão/discriminação, na hibridização das formas de domínio do capital e da colonização do poder." (CARVALHO, 2010, p. 180).

De acordo com o relatório acerca dos povos indígenas na América Latina (CEPAL, 2015, p. 40), entende-se que, segundo os dados censitários, para o ano de 2010 , a população indígena estimada na América Latina era em torno de 45 milhões de pessoas, das quais 17 milhões viviam no México e outros 7 milhões, no Peru. Entretanto, os países com maior proporção de população indígena são: Bolívia (62,2\%), Guatemala (41,0\%), Peru $(24,0 \%)$ e México (15,1\%).

O Brasil possui a maior quantidade de povos indígenas (305), seguido pela Colômbia (102), Peru (85), México (78) e Bolívia (39). Muitos deles estão em perigo de desaparecimento físico ou cultural, como se pode constatar nos casos do Brasil (70 povos em risco), Colômbia (35) e Bolívia (13). Vale ressaltar que o Peru não considerou o critério de autoidentificação nos seus últimos censos. (CEPAL, 2015, p. 40)

Portanto, nota-se que o Peru e a Bolívia têm posições de destaque em relação à grande diversidade de povos indígenas e à proporção de população indígena quando comparada à polução total, o que demonstra a necessidade de reconhecimento desses povos para alcançar o desenvolvimento humano e o crescimento econômico.

Com o objetivo de compor uma base comparativa entre Peru e Bolívia, empreendeu-se pesquisa em dados oficiais os mais atualizados possíveis. Como resultado, compôs-se a seguinte tabela, a fim de demonstrar a conciliação entre desenvolvimento humano, crescimento econômico e previsão constitucional para efetivar e garantir os direitos humanos.

Tabela 1 - Desenvolvimento humano e crescimento econômico do Peru e da Bolívia

\begin{tabular}{|c|c|c|}
\hline Dados/País & Peru & Bolívia \\
\hline Índice de Capital Humano $(2016)^{3}$ & 66,31 (79 posição) & 66,47 (77º posição) \\
\hline Doing Business $(2017)^{4}$ & 70,25 (54 posição) & 49,85 (149 posição) \\
\hline IDH $(2016)^{5}$ & 0,740 (870 posição) & 0,674 (118 posição) \\
\hline PIB per capita $(2015)^{6}$ & 6029 dólares & 3073 dólares \\
\hline
\end{tabular}

Fonte: Tabela de autoria própria elaborada por intermédio dos dados extraídos em órgãos oficiais. (WORLD ECONOMIC FORUM, 2016, online), (THE WORLD BANK, 2017, online), (PNUD, 2016, online) e (CEPAL, 2015, online).

3 O Índice de Capital Humano quantifica como 130 países estão implantando o Capital Humano por meio da avaliação dos resultados de aprendizagem e emprego. Em outras palavras este índice mede a capacidade dos países de maximizar e alavancar sua dotação de capital humano. A partir do último relatório de 2016, percebe-se que os líderes do índice são economias de alta renda que combinam ensino superior de alto nível de escolaridade e uma proporção correspondente de sua força de trabalho nas ocupações de alta qualificação (WORLD ECONOMIC FORUM. The Human Capital Report 2016).

4 O Relatório do Doing Business 2017, voltado nomeadamente para a compreensão da regulamentação para as pequenas e médias empresas, organizado pelo Banco Mundial e pelo Banco Internacional de Reconstrução e Desenvolvimento (BIRD), compara a produção de regras de negócios para as empresas nacionais nas economias do mundo. Em outras palavras, informa quais os melhores países para se investir (THE WORLD BANK. Doing Business 2017: Equal Opportunity for all, 2017).

5 O Índice de Desenvolvimento Humano (IDH) é uma medida resumida do progresso a longo prazo em três dimensões básicas do desenvolvimento humano: renda, educação e saúde. O objetivo da criação do IDH foi o de oferecer um contraponto a outro indicador muito utilizado, o Produto Interno Bruto (PIB) per capita, que considera apenas a dimensão econômica do desenvolvimento. O último relatório de 2016 inclui o Índice de Desenvolvimento Humano e apresenta dados e análises relevantes à agenda global e aborda questões e políticas públicas que colocam as pessoas no centro das estratégias de enfrentamento aos desafios do desenvolvimento. - PNUD. Programa das Nações Unidas para o desenvolvimento (PNUD). Relatório do Desenvolvimento Humano 2016: Desenvolvimento humano para todos.

6 O Produto Interno Bruto (PIB) per capita é um índice que considera a dimensão econômica do desenvolvimento, é o PIB dividido pela quantidade de habitantes de um país. O PIB é a soma de todos os bens de um país, e quanto maior o PIB, mais demonstra o quanto esse país é desenvolvido, e podem ser classificados entre países pobres, ricos ou em desenvolvimento. O último dado obtido foi de 2015 pela CEPAL. CEPAL. Comissão Econômica para a América Latina e o Caribe. CEPALSTAT. Bases de datos y publicaciones estadísticas. Perú: Perfil Nacional Econômico. 2015 (2017c); CEPAL. Comissão Econômica para a América Latina e o Caribe. CEPALSTAT. Bases de datos y publicaciones estadísticas. Bolívia (Estado Plurinacional de): Perfil Nacional Econômico. 2015 (2017d). 
A partir dessa tabela, nota-se que, quanto ao Índice de Capital Humano, os dois países estão bem próximos no ranking com posições desvantajosas, o que demonstra que a relação aprendizagem e emprego em tais países está um pouco atrasada, não se desenvolvendo tanto neste ponto. Em outras palavras, os dois países têm baixa capacidade de maximizar e alavancar a dotação de capital humano.

Vale ressaltar que investir em capital humano vai além de uma necessidade econômica, pois é a base para que todos os indivíduos vivam ao máximo seu potencial, principalmente diante das inovações tecnológicas que caracterizam a Quarta Revolução Industrial.

Para Alba de Carvalho (2010, p. 177), "a ação expansiva do capital e suas formas de dominação abstrata comprometem a vida, a cultura e o bem-estar". A vida econômica não deve ser submetida à ilimitada acumulação do capital privado, deve, portanto, organizar-se no sentido de atender às necessidades e utilidades públicas (COMPARATO, 2001, p. 445-470).

Quanto aos outros índices analisados, percebe-se que o Peru tem maior crescimento econômico, maior avaliação em relação à procura para investimentos externos e maior desenvolvimento humano quando comparado com a Bolívia. Especificamente quanto ao Índice de Desenvolvimento Humano de 2016, o Peru se enquadra na categoria de alto desenvolvimento humano, enquanto que a Bolívia está no médio desenvolvimento humano.

Então, uma economia frágil, desigual e diversa dificulta o desenvolvimento humano, principalmente quando mais da metade da população é indígena, como no caso da Bolívia, e ainda não é valorizada economicamente. Vale ressaltar que "nos últimos anos, muita atenção tem sido dada à importância das instituições para o desenvolvimento econômico." (FUKUYAMA, 2010, p. 229).

Promover a compreensão intercultural, a tolerância, o respeito mútuo e uma ética de cidadania global e de responsabilidade compartilhada são essenciais para o desenvolvimento humano. É importante ainda ter ciência da diversidade natural e cultural do mundo, e reconhecer que todas as culturas e civilizações podem contribuir para o desenvolvimento sustentável, constituindo-se como elementos cruciais para tanto.

Com o objetivo de reconhecer a necessidade de se construir sociedades pacíficas, justas e inclusivas que ofereçam igualdade de acesso à justiça e que tenham como fundamento o respeito aos direitos humanos, o efetivo Estado de Direito e a boa governança em todos os níveis e em instituições transparentes, eficazes e responsáveis, foi feita a Agenda de Desenvolvimento Sustentável Pós2015, também chamada de Agenda 2030. Esse documento corresponde a um conjunto de programas, ações e diretrizes que orientarão os trabalhos das Nações Unidas e de seus países-membros rumo ao desenvolvimento sustentável. É um plano de ação para as pessoas, o planeta e a prosperidade (ONU, 2016, online).

Concluídas em agosto de 2015, as negociações da Agenda 2030 culminaram em documento que propõe 17 Objetivos do Desenvolvimento Sustentável (ODS) e 169 metas correspondentes, fruto do consenso obtido pelos delegados dos Estados-membros da ONU. Os ODS são o cerne da Agenda 2030, e sua implementação ocorrerá no período 2016-2030 (ONU, 2016, online).

A Agenda 2030 converge com os esforços realizados pela Comissão Econômica para a América Latina e o Caribe (CEPAL) para apoiar a análise e formulação de políticas para a igualdade e a mudança estrutural. Contudo, alguns temas importantes para a região não são adequadamente considerados, a exemplo dos povos indígenas e os grupos afrodescendentes, que representam uma alta proporção da população da América Latina e do Caribe, cujos direitos e problemas específicos não são contemplados.

Não há nenhum objetivo da Agenda 2030 que contemple especificamente os índios, porém existe referência a eles no objetivo 2 (acabar com a fome, alcançar a segurança alimentar e melhoria da nutrição e promover a agricultura sustentável) quando trata especificamente em dobrar a produtividade agrícola e, no objetivo 4 (assegurar a educação inclusiva e equitativa de qualidade, e promover oportunidades de aprendizagem ao longo da vida para todos), quando trata acerca de eliminar as disparidades de gênero na 
educação e garantir a igualdade de acesso a todos os níveis de educação e formação profissional para os mais vulneráveis (ONU, 2016, online).

Além disso, os povos indígenas, considerados como parte integrante e atuante da sociedade, devem ser considerados para a efetivação de diversos objetivos, a exemplo dos objetivos 3 (assegurar uma vida saudável e promover o bem-estar para todos, em todas as idades), 10 (reduzir a desigualdade dentro dos países e entre eles) e 16 (promover sociedades pacíficas e inclusivas para o desenvolvimento sustentável, proporcionar o acesso à justiça para todos e construir instituições eficazes, responsáveis e inclusivas em todos os níveis), pois só assim haverá desenvolvimento sustentável que proporcionará uma conciliação entre crescimento econômico e desenvolvimento humano.

Os povos indígenas foram posicionando seus direitos nas legislações e instituições dos Estados em um processo difícil e que continua no presente. A efetividade do sistema legal formal para todos os grupos sociais, sem distinções por categorias ou distribuição territorial da população, é um indicador do grau de realização democrática na nação (O’DONNELL, 2007, p. 168-171).

A partir do estudo comparativo, compreende-se que um avanço na previsão constitucional de direitos e garantias, que entende os povos indígenas como nações, não é por si só fator determinante para um aumento do desenvolvimento humano. Deve-se ter a atuação conjunta do público e do privado para proporcionar uma sociedade plena e democrática, conforme se infere:

La vigência de una ciudadania relativamente plena ayuda a generar patrones de desigualdad que son menos agudos, y social y politicamente menos destructivos que los caracterizan los países donde, em el mejor de los casos, solo los derechos políticos se mantienem mas o menos plenamente (O'DONNELL, 2007, p. 174-175).

Além do reconhecimento dos direitos dos povos indígenas pela esfera pública, as diversas instituições, como igrejas, associações civis e sociedades empresárias, devem se adequar no reconhecimento dessas nações, anteriormente desprezadas, para que toda a sociedade possa ter um pleno desenvolvimento sem desigualdades tão acentuadas.

O desenvolvimento sustentável não pode ser levado a cabo sem paz e segurança; que estarão em risco sem o desenvolvimento sustentável. É interessante haver uma cooperação para remover os obstáculos à plena realização do direito de autodeterminação dos povos, que continua a afetar negativamente o seu desenvolvimento econômico e desenvolvimento social, bem como o seu meio ambiente.

\section{Conclusão}

Constata-se, que no século XXI, há tendências por novos movimentos constitucionais na América Latina, que estão relacionados com a exigência popular por melhores condições de vida e buscam refundar instituições políticas e jurídicas inclusivas. O constitucionalismo latino-americano, com tendência plurinacional, prioriza a riqueza cultural diversificada, respeita as tradições comunitárias históricas e supera o modelo de política exclusivista.

Nesse sentido, esse movimento contemporâneo aborda questões inovadoras, que rompem com os velhos paradigmas políticos do direito e compreendem a interdependência e cooperação do público e do privado, bem como reconhece a diversidade de instituições sociais, como igrejas, sindicatos, associações civis e sociedades empresárias.

Na mesma esteira de raciocínio, para a satisfação da plurinacionalidade e do Estado participativo, deve-se ter em conta as complexidades e diversidades das visões do direito e da justiça. O constitucionalismo latino-americano reconhece os povos, diferentes culturas e busca protegê-las. Além disso, proporciona discussão e promove mecanismos para a autonomia política, juntamente com reconhecimento de regras de convivência de caráter normativo. 
Os movimentos pela refundação do Estado latino-americano surgem da exigência histórica por espaço democrático e congregam interesses a partir do abandono da posição de sujeitos passivos na relação social com os poderes instituídos. Assim, para a emancipação individual, faz-se premente o incremento de capital humano, posto que é ferramenta essencial para garantir o desenvolvimento dos direitos de personalidade. A condição de agência pressupõe autonomia e responsabilidade. Logo, o reconhecimento de todos os povos como sujeito de direitos, principalmente aqueles que foram marginalizados nos períodos históricos, como os povos indígenas. O homem é agente da sociedade, nesse viés, interesses individuais e coletivos devem progredir concomitantes.

A partir da análise comparativa entre Peru e Bolívia, conclui-se que os dois países têm bastante diversidade de povos indígenas e significante contingente populacional de índios em relação à população total. A Bolívia possui uma Constituição plurinacional, enquanto que o Peru adota uma Constituição pluricultural, o que significa que a Constituição bolivariana está num ciclo progressivo do constitucionalismo pluralista mais avançado que a peruana.

Contudo, assim como o crescimento econômico não acarreta nem a integração social nem a diminuição das desigualdades, a previsão constitucional de direitos e garantias dos povos indígenas, e até mesmo a sua consideração como nação, não é suficiente para a garantia do desenvolvimento humano, pois é necessário, além disso, transformações em diferentes níveis ou espaços: individual, familiar, comunitário, local, nacional e internacional.

Para proporcionar desenvolvimento na América Latina, é necessário um esforço conjunto entre o público e privado, capaz de conciliar o crescimento econômico com o desenvolvimento humano sustentável. A população e os governos devem estar envolvidos nas escolhas e resultados, assim as decisões devem ser tomadas com responsabilidade.

A cooperação entre os países é complementar à política interna e deve estar voltada para desenvolver instituições eficazes, responsáveis e transparentes, de modo a permitir a inclusão das pessoas e dos países, bem como distribuir resultados. Vale ressaltar que não há inclusão sem políticas específicas de distribuição de renda e acesso a serviços essenciais, baseados na realidade econômica de cada país.

Reitera-se que a força capaz de promover o desenvolvimento e retirar os países da dependência está no reconhecimento das diferenças e na busca por protegê-las e integrá-las socialmente. Só a formação do capital humano e o respectivo desenvolvimento das capacidades serão instrumentos possíveis e viabilizadores da consecução do desenvolvimento sustentável.

\section{Referências}

BOLÍVIA. Estado Plurinacional da Constitución del Estado (CPE). 7 feb. 2009. Disponível em: <https://www.oas.org/dil/esp/Constitucion_Bolivia.pdf>. Acesso em: 21 maio 2017.

BRAGATO, Fernanda Frizzo; BARRETTO, Vicente de Paulo; SILVEIRA FILHO, Alex Sandro da. A interculturalidade como possibilidade para a construção de uma visão de direitos humanos a partir das realidades plurais da América Latina. Revista da Faculdade de Direito UFPR, Curitiba, v. 62, n. 1, p. 33-59, jan./abr. 2017. Disponível em: <http://revistas.ufpr.br/direito/article/view/47133>. Acesso em: 30 abr. 2017.

CARVALHO, Alba Maria Pinho de. Políticas públicas e o dilema de enfrentamento das desigualdades: um olhar crítico sobre a América Latina no século XXI. In: SOUSA, Fernando José Pires de. Poder e políticas públicas na América Latina. Fortaleza: UFC, 2010. p. 171-200.

CARVALHO, Nathalie de Paula; POMPEU, Gina Vidal Marcílio. Do neoliberalismo ao neossocialismo: a experiência do Peru. In: POMPEU, Gina Vidal Marcílio; HISSA, Carolina Soares (Org.). O escopo do Estado e das instituições nos países da América do Sul e a inserção na economia global. Fortaleza: Premius, 2010. p. 159-174. 
COMISSÃO ECONÔMICA PARA A AMÉRICA LATINA E O CARIBE - CEPAL. Bases de datos y publicaciones estadísticas. Perú: Perfil Nacional Socio-demográfico. 2017a. Disponível em: <http:// estadisticas.cepal.org/cepalstat/Perfil_Nacional_Social.html?pais=PER\&idioma=spanish>. Acesso em: 21 maio 2017.

COMISSÃO ECONÔMICA PARA A AMÉRICA LATINA E O CARIBE - CEPAL. Bases de datos y publicaciones estadísticas. Bolívia (Estado Plurinacional de): Perfil Nacional Sociodemográfico. 2017b. Disponível em: < http://estadisticas.cepal.org/cepalstat/Perfil_Nacional_Social. html?pais=BOL\&idioma=spanish>. Acesso em: 21 maio 2017.

COMISSÃO ECONÔMICA PARA A AMÉRICA LATINA E O CARIBE - CEPAL. Bases de datos y publicaciones estadísticas. Perú: perfil nacional econômico. 2015a. Disponível em: <http://estadisticas. cepal.org/cepalstat/Perfil_Nacional_Economico.html?pais=PER\&idioma=spanish>. Acesso em: 21 maio 2017.

COMISSÃO ECONÔMICA PARA A AMÉRICA LATINA E O CARIBE - CEPAL. Bases de datos y publicaciones estadísticas. Bolívia (Estado Plurinacional de): perfil nacional econômico. 2015b. Disponível em: < http://estadisticas.cepal.org/cepalstat/Perfil_Nacional_Economico. html?pais=BOL\&idioma=spanish>. Acesso em: 21 maio 2017.

COMISSÃO ECONÔMICA PARA A AMÉRICA LATINA E O CARIBE - CEPAL. Os povos indígenas na América Latina: avanços na última década e desafios pendentes para a garantia de seus direitos. 2015c. Disponível em: <http://repositorio.cepal.org/bitstream/handle/11362/37773/1/S1420764_pt.pdf>. Acesso em: 21 maio 2017.

COMPARATO, Fábio Konder. A afirmação histórica dos direitos humanos. 2. ed. São Paulo: Saraiva, 2001.

DWORKIN. Ronald. Levando os direitos a sério. Tradução de Nelson Boeira. São Paulo: Martins Fontes, 2002.

FERNÁNDEZ, Raúl Llasag. Constitucionalismo plurinacional e intercultural de transição: Equador e Bolívia. Méritum: Revista de Direito da Universidade FUMEC, Belo Horizonte, v. 9, n. I, p. 265-294, jan./ jun. 2014.

FURTADO, Celso. Subdesenvolvimento e estagnação na América Latina. Rio de Janeiro: Civilização Brasileira, 1968.

FUKUYAMA, Francis. Ficando para trás: explicando a crescente distância entre América Latina e Estados Unidos. Tradução de Nivaldo Montingelli Jr. Rio de Janeiro: Rocco, 2010.

KONZEN, Lucas Pizzolatto. A teoria do pluralismo jurídico e os espaços públicos urbanos. Sequência, Florianópolis, v. 31, n. 61, p. 227-250, dez. 2010. Disponível em: <https://periodicos.ufsc.br/index.php/ sequencia/article/view/2177-7055.2010v31n61p227/17284>. Acesso em: 21 maio 2017.

LOUREIRO, Silvia Maria da Silveira; MARTINS, Marcello Phillipe Aguiar; SILVA, Caio Henrique Faustino da. O princípio de humanidade e os conflitos interculturais: os desafios e possibilidades do novo constitucionalismo latino-americano indigenista. In: TRINDADE, Antônio Augusto Cançado; LEAL, César Barros (Coord.). $O$ princípio de humanidade e a salvaguarda da pessoa humana. Fortaleza: Expressão, 2016. p. 365-390.

O'DONNELL, Guillermo. Dissonancias: Críticas democráticas a la democracia. Buenos Aires: Prometeo Libros, 2007.

ORGANIZAÇÃO DAS NAÇÕES UNIDAS. Agenda de Desenvolvimento Sustentável Pós2015: Agenda 2030. 2016. Disponível em: <http://www.itamaraty.gov.br/images/ed_desenvsust/ Agenda2030completoportugus12fev2016.pdf>. Acesso em: 21 maio 2017.

PERU. Constituição (1993). Constitucion política del Perú. Disponível em: <http://www.minsa.gob.pe/ renhice/documentos/constitucion.pdf>. Acesso em: 21 maio 2017.

POMPEU, Gina Vidal Marcílio. O retorno do Estado- Nação na geografia da mundialização In: CONGRESSO NACIONAL DO CONPEDI/BRASÍLIA-DF, XVII, 2008, Florianópolis. Anais... 
Desenvolvimento Econômico e Política Fiscal. Florianópolis: Fundação Boiteux, 2008, p.1330-1345. Disponível em: <https://s3.amazonaws.com/conpedi2/anteriores/XVII+Congresso+Nacional+-+Bras\%C3 \%ADlia+(20\%2C+21+e+22+de+novembro+de+2008).pdf>. Acesso em: 17 maio 2017.

PROGRAMA DAS NAÇÕES UNIDAS PARA O DESENVOLVIMENTO - PNUD. Relatório do Desenvolvimento Humano 2016: Desenvolvimento humano para todos. Disponível em: < http://www. br.undp.org/content/dam/brazil/docs/RelatoriosDesenvolvimento/undp-br-2016-human-developmentreport-2017.pdf>. Acesso em: 21 maio 2017.

SANTOS, Boaventura de Sousa. Refundación del Estado em América Latina: perspectivas desde una epistemologia del Sur. Lima: Instituto Internacional de Derecho y Sociedad, 2010.

SANTOS, Boaventura de Sousa. Pensar el Estado y la sociedad: desafios actuales. Buenos Aires: Waldhuter, 2009.

THE WORLD BANK. Doing business 2017: equal opportunity for all. Disponível em: <http://www. doingbusiness.org/reports/global-reports/doing-business-2017>. Acesso em: 21 maio 2017.

TOURAINE, Alain. Palavra e sangue: política e sociedade na América Latina. Tradução de Iraci D. Poleti. Campinas: Universidade Estadual de Campinas, 1989.

WORLD ECONOMIC FORUM. The Human Capital Report 2016. Disponível em: <http://reports. weforum.org/human-capital-report-2016/>. Acesso em: 21 maio 2017.

WOLKMER, Antonio Carlos. Pluralismo jurídico: fundamentos de uma nova cultura do direito. 3. ed. São Paulo: Alfa Omega, 2001.

WOLKMER, Antonio Carlos; FAGUNDES, Lucas Machado. Tendências contemporâneas do constitucionalismo latino-americano: Estado plurinacional e pluralismo jurídico. Pensar - Revista de Ciências Jurídicas, Fortaleza, v. 16, n. 2, p. 371-408, jul./dez. 2011.

Recebido em: 09/06/2017

Aprovado em: 09/11/2017 